\title{
Removal of As(III) from Aqueous Solution Using Fe(III) Loaded Pomegranate Waste
}

\author{
Sheela Thapa and Megh Raj Pokhrel ${ }^{*}$ \\ Central Department of Chemistry, Tribhuvan University, Kirtipur, Kathmandu, Nepal \\ E-mail:meghraj11@hotmail.com
}

\begin{abstract}
A study on As(III) removal using Fe(III) loaded pomegranate waste as an adsorbent is presented. The effects of initial metal ion concentration, contact time, adsorbent dose and $\mathrm{pH}$ of the solution on the removal of arsenic were investigated in a batch system. The optimum $p H$ for As(III) adsorption using $\mathrm{Fe}$ (III)-loaded charred pomegranate waste [Fe-CPW] was found to be 9. The equilibrium has been achieved in 2 hours. The maximum adsorption capacity $\left(q_{\max }\right)$ for the adsorption of As (III) was found to be $50 \mathrm{mg} / \mathrm{g}$. The experimental data fitted well with the Langmuir adsorption isotherm model.
\end{abstract}

Keywords: Pomegranate waste, adsorption capacity, spectrophotometer, adsorption isotherm

\section{Introduction}

Arsenic is of environmental concern due to its toxicity and carcinogenicity. Drinking water has been identified as one of the major source of arsenic exposure for the general population. Concerns over possible health risks associated with the chronic ingestion of low levels of arsenic in drinking water have increased. As(III) is more toxic, soluble and mobile than $\mathrm{As}(\mathrm{V})$. Drinking arsenic rich water over a long period can result in various adverse health effects including skin problems, skin cancer, cancers of bladder, kidneys and lungs, disease of the blood vessels of the legs and feet, and possibly also diabetes, high blood pressure and reproductive disorders ${ }^{1}$.

Although environmental restrictions and regulations have limited the productions and uses of arsenic and its compounds, they are still extensively used in metallurgy, agriculture, forestry, electronics, pharmaceuticals, glass and ceramic industries, etc. Arsenic being one of the most toxic pollutants introduced into the environment through the weathering of rocks and minerals, industrial wastes discharges, fertilizers, agricuitural employments of pesticides, smelting of metal and burning of fossil fuels ${ }^{2,3}$.

Arsenic occurs in $-3,0,+3$ and +5 oxidation states in aquatic systems. The elemental state is extremely rare whereas -3 oxidation state is found only at extremely reducing conditions. Arsenate species (pentavalent state) are stable in oxygenated waters. Under mild reducing conditions, arsenite (trivalent state) predominates. Arsenic combines strongly with carbon in arsenical organic compounds which are used as pesticides, chemotherapeutic agents and chemical warfare agents. The toxicity of arsenic firmly depends upon its oxidation state and trivalent arsenic is more toxic than pentavalent and organic arsenicals ${ }^{4,5}$.

Arsenic contamination of drinking water resources is a global crisis. However, this problem is more acute in countries like Bangladesh, India, Taiwan, China and Terai belt of Nepal ${ }^{6}$. Therefore, processes to remove arsenic from drinking water are urgently required. 
Numerous arsenic removal technologies such as co-precipitation, liquid-liquid extraction, ion exchange, ultrafiltration, adsorption etc. have been so far used for arsenic removal. Among them, adsorption methods are considered to be most promising technologies because of simplicity to operate and cost effective. Many attempts have been made regarding the removal of arsenite and arsenate by using iron(III) loaded chelating ion exchange resins having their acidic or basic moiety as functional group ${ }^{7}$. But treatments with the resins are expensive and not affordable to the people of developing countries. In the present study, a low cost bioadsorbent prepared from pomegranate waste for the removal of As(III) from aqueous solution has been investigated.

\section{Experimental Methods}

\section{Analysis}

The $\mathrm{pH}$ of the sample solution was measured by using $\mathrm{pH}$ meter (LI613, ELICO, Type 245 with glass electrode).The stock solutions of As(III) was prepared from arsenic trioxide $\left[\mathrm{As}_{2} \mathrm{O}_{3}\right]$ and was diluted to the desired concentrations. The wavelength for maximum absorption $\left[\lambda_{\max }\right]$ and calibration curve were obtained by using WPA-S104 spectrophotometer. The concentration of arsenic was determined with the help of calibration curve by spectrophotometric molybdenum blue method.

For the preparation of calibration curve arsenic solution containing 50, 100, 200, 300, 400, 500, 600, 700,800 and $900 \mu \mathrm{g} / \mathrm{L}$ were prepared in $25 \mathrm{ml}$ volumetric flask by the following procedure:

The required amount of diluted solutions of As(III) were pipetted out and transferred into $25 \mathrm{~mL}$ volumetric flasks. To each flask $4.5 \mathrm{~mL}$ sulphuric acid $(1.5 \mathrm{~N}), 3$ drops (from $1 \mathrm{~mL}$ pipette) of potassium permanganate $(0.1 \mathrm{~N}), 3 \mathrm{~mL}$ ammonium molybdate $(0.5 \%)$ and $3 \mathrm{~mL}$ of hydrazine hydrate $(0.5 \mathrm{M})$ solutions were added. Then the volume was made upto the mark by adding distilled water. For maximum complex formation, the above solutions were left for 20 minutes at room temperature. The absorbance of each solution was measured at $840 \mathrm{~nm}$ against blank solution by WPA S104 spectrophotometer.

\section{Preparation of Adsorbents}

\section{Preparation of Raw Pomegranate Waste [RPW]}

Crude pomegranate fruit waste was collected from a local juice shop located at Kirtipur, Kathmandu. The waste was washed and cleaned and then dried in sunlight for a week. The fully dried waste was powdered in grain crusher. It was again dried in sunlight for about 3 days and crushed very finely into powder in the grain crusher. The finely powdered raw adsorbent [designated as RPW] was sieved to particle size of $212 \mu \mathrm{m}$ and packed in an air tight bottle.

\section{Modification of raw pomegranate adsorbent [RPW]}

$5 \mathrm{gm}$ of RPW was treated with $10 \mathrm{~mL}$ of concentrated sulphuric acid (1:2, W/V ratio). The mixture was allowed to soak for 24 hours at room temperature. Then it was washed with distilled water until the $\mathrm{pH}$ was neutral and filtered. The adsorbent was dried at $100{ }^{\circ} \mathrm{C}$ for 6 hours in hot air oven, grinded to get powder form and sieved to $212 \mu \mathrm{m}$ particle size. The adsorbent is designated as CPW.

\section{Preparation of Fe (III)-loaded pomegranate waste [Fe-CPW]}

$20 \mathrm{~g}$ of CPW was mixed with $500 \mathrm{~mL}$ of $1.5 \times 10^{-2} \mathrm{M}$ anhydrous ferric chloride solution maintained at pH 3 and stirred for 24 hours. Then it was filtered and washed with distilled water until $\mathrm{pH}$ of the filtrate was neutral, finally the adsorbent [designated as $\mathrm{Fe}-\mathrm{CPW}$ ] was dried for 24 hours at $100{ }^{\circ} \mathrm{C}$. It was sieved to particle size of $212 \mu \mathrm{m}$. This material was used for removal of arsenic under batch adsorption processes. 


\section{Batch adsorption studies}

Batch adsorption studies were carried out with Fe-CPW to determine the adsorption of As(III). The effects of $\mathrm{pH}$ (6-12) of the solution, initial concentration of metal ion (10 to $500 \mathrm{mg} / \mathrm{L}$ ), contact time (5 to 130 minutes) and amount of adsorbent ( 25 to $60 \mathrm{mg}$ ) on the adsorption process were studied. The solution $\mathrm{pH}$ was adjusted by using $3 \mathrm{M} \mathrm{HCl}$ or $3 \mathrm{M} \mathrm{NaOH}$ solutions. Batch adsorption studies were carried out by taking $25 \mathrm{~mL}(20 \mathrm{mg} / \mathrm{L})$ of $\mathrm{As}(\mathrm{III})$ solutions in $125 \mathrm{~mL}$ stoppered bottles. The required amount $(25 \mathrm{mg})$ of adsorbent was then added and the flask contents were shaken for the required contact time at room temperature using mechanical shaker. The solutions were filtered immediately through Whatman-41 filter paper and filtrates were analyzed for the equilibrium concentration of As(III).

From the concentration measured before and after adsorption $\left(\mathrm{C}_{\mathrm{o}}\right.$ and $\mathrm{C}_{\mathrm{e}}$ respectively) and dry weight of adsorbent (W) as well as volume of aqueous solution (V), the uptake capacity of metal ions (q) and the removal percentage (R\%) were calculated according to equation (1) and equation (2):

$$
\begin{aligned}
& \mathrm{q}=\frac{\mathrm{C}_{\mathrm{o}}-\mathrm{C}_{\mathrm{e}}}{\mathrm{W}} \times \mathrm{V}(\mathrm{mg} / \mathrm{g}) \\
& \mathrm{R}(\%)=\frac{\mathrm{C}_{\mathrm{o}}-\mathrm{C}_{\mathrm{e}}}{\mathrm{C}_{\mathrm{o}}} \times 100
\end{aligned}
$$

\section{Results and Discussion}

\section{Absorption spectra and calibration curve}

Figure 1 shows the position of the absorbance maxima for the arsenomolybdenum blue complex. The position of the absorbance maxima for arsenomolybdenum blue complex occurs at $840 \mathrm{~nm}$. This wavelength, $840 \mathrm{~nm}$ was selected for quantitative determination of arsenic in water ${ }^{8}$. Figure 2 shows the plot of absorbance as a function of As(III) concentration [calibration curve]. The plot is linear upto 900 $\mathrm{ug} / \mathrm{L}$ of $\mathrm{As}(\mathrm{III})$ concentration, which indicates the validity of Beers-Lambert law up to this concentration range.

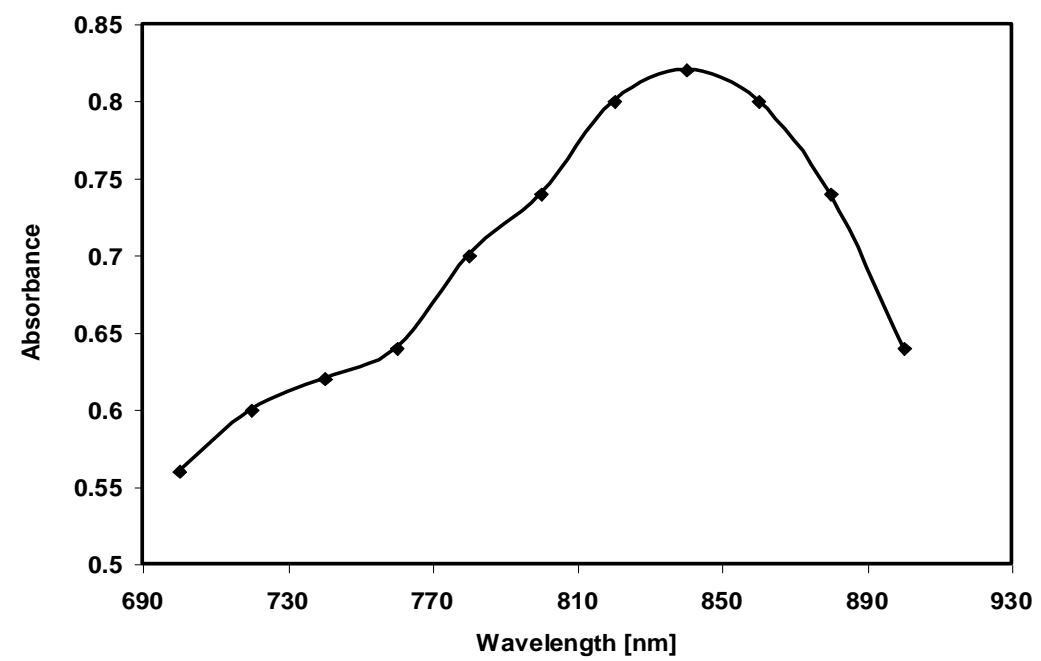

Figure 1: Absorption spectra of arsenomolybdenum blue complex measured with a WPA S104 spectrophotometer. 


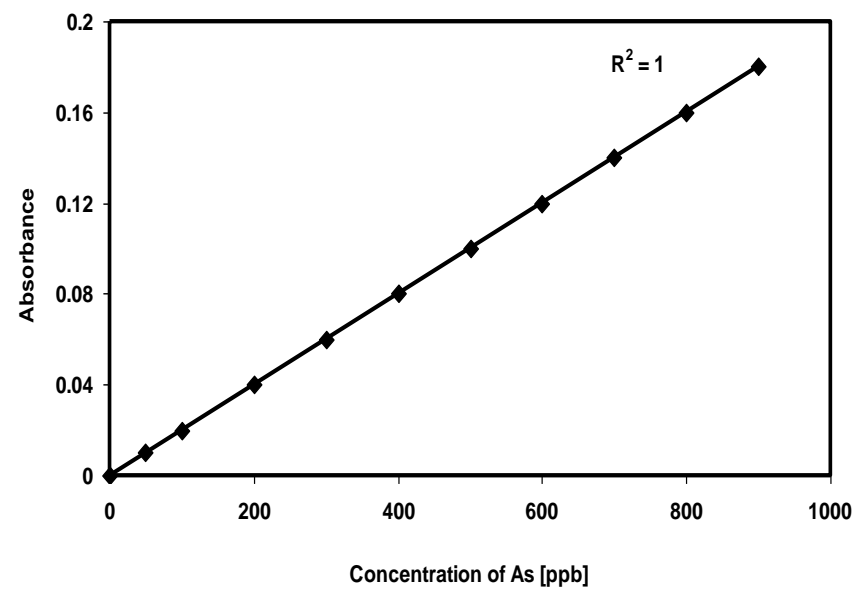

Figure 2: Calibration curve for determination of As(III)

\section{Batch Studies}

\section{Effect of pH on As(III) adsorption}

It is well known that the $\mathrm{pH}$ of the medium affects the solubility of metal ions and the concentration of the counter ions on the functional groups of the adsdorbent, so the adsorption of arsenic is highly $\mathrm{pH}$ dependent process. The effect of equilibrium $\mathrm{pH}$ on the adsorption of As(III) onto Fe-CPW is shown in Figure 3 , which shows the relationship between removal percentage and equilibrium $\mathrm{pH}$ in the adsorption of $\mathrm{As}(\mathrm{III})$ onto Fe-CPW at an initial concentration of $20 \mathrm{mg} / \mathrm{L}$.

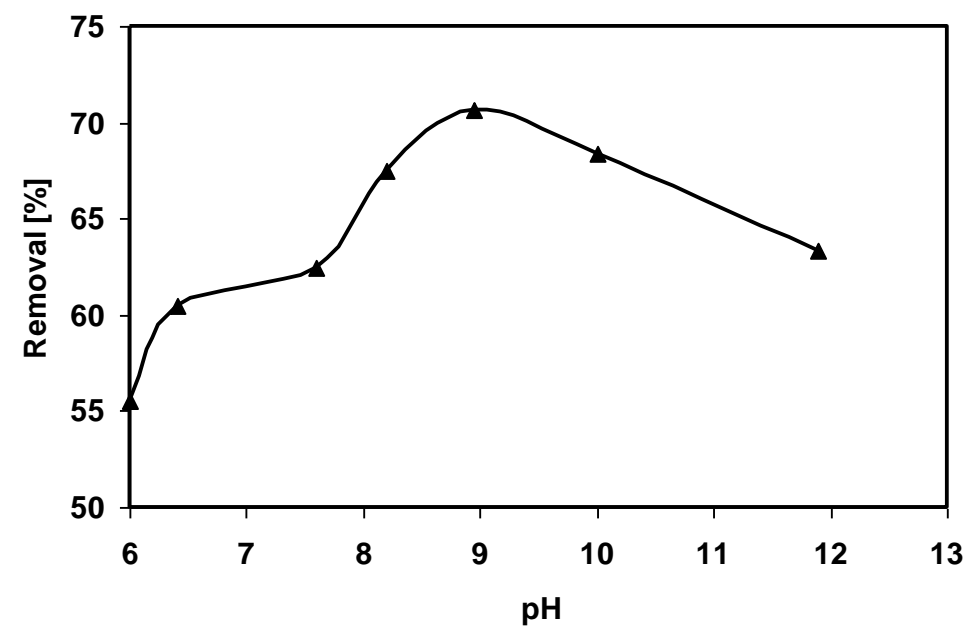

Figure 3: Effect of $p H$ on adsorption of As(III) onto Fe-CPW

Maximum removal of As(III) was found to be at $\mathrm{pH} 9$ which was $70.7 \%$. Hence the $\mathrm{pH} 9$ was designated as optimum $\mathrm{pH}$ for further studies. It was found that the adsorption of As(III) was lower at lower $\mathrm{pH}$, attained maximum value at $\mathrm{pH} 9$ and declined with increase in $\mathrm{pH}$. The relative distribution of dissolved arsenic 
species, $\mathrm{As}(\mathrm{III})$ is influenced by $\mathrm{pH}$ and redox conditions. In solution up to $\mathrm{pH} 8, \mathrm{As}(\mathrm{III})$ exists principally as undissociated $\mathrm{H}_{3} \mathrm{AsO}_{3}$. The predominant monoionic $\left(\mathrm{H}_{2} \mathrm{AsO}_{3}{ }^{-}\right)$and neutral $\left(\mathrm{H}_{3} \mathrm{AsO}_{3}\right)$ species are thus considered to be responsible for adsorption of As(III) by substitution of the hydroxyl ions or water molecules at $\mathrm{pH}$ 9. The $\mathrm{As}(\mathrm{III})$ is inferred to be adsorbed onto Fe-CPW by ligand exchange reaction ${ }^{9}$. The increase or decrease in adsorption capacity with $\mathrm{pH}$ may be attributed on the basis of surface functional charge of the adsorbent, the degree of ionization and the specification of surface functional groups ${ }^{10}$.

\section{Adsorption isotherms}

The main objective of isotherm study is to evaluate the capacity of the modified bioadsorbent to sequester $\mathrm{As}(\mathrm{III})$ from an aqueous solution. It was done by characterizing the equilibrium state of the $\mathrm{Fe}$ CPW that has been allowed to react with aqueous solution of As(III). The isotherm studies were performed using various initial concentrations of $\mathrm{As}(\mathrm{III})(10 \mathrm{mg} / \mathrm{L}$ to $500 \mathrm{mg} / \mathrm{L})$ to which a constant weight $(25 \mathrm{mg}$ ) of adsorbent and a volume of $25 \mathrm{~mL}$ of As(III) at optimum pH was applied in $125 \mathrm{~mL}$ stoppered bottles. The Langmuir and Freundlich models were used to analyze adsorption data.

The Langmuir equation applied for adsorption equilibrium is as follows ${ }^{11}$ :

$$
\mathrm{C}_{\mathrm{e}} / \mathrm{q}_{\mathrm{e}}=1 / \mathrm{q}_{\mathrm{m}} \mathrm{b}+\mathrm{C}_{\mathrm{e}} / \mathrm{q}_{\mathrm{m}}
$$

Where $\mathrm{C}_{\mathrm{e}}$ is the equilibrium concentration $(\mathrm{mg} / \mathrm{L}), \mathrm{q}_{\mathrm{e}}$ the amount adsorbed under equilibrium $(\mathrm{mg} / \mathrm{L}), \mathrm{q}_{\mathrm{m}}$ the theoretical maximum adsorption capacity corresponding to complete monolayer coverage $(\mathrm{mg} / \mathrm{g})$, and $\mathrm{b}(\mathrm{l} / \mathrm{mg})$ is a Langmuir constant related to the enthalpy of adsorption. $\mathrm{q}_{\mathrm{m}}$ and $\mathrm{b}$ are determined from the slope and intercept of the plot of $\mathrm{C}_{\mathrm{e}} / \mathrm{q}_{\mathrm{e}}$ versus $\mathrm{C}_{\mathrm{e}}$. The value of $\mathrm{R}^{2}$ can be regarded as a measure of the quality of fit of experimental data on isotherm models. The adsorption data could be described well by Langmuir model for As(III) $\left(\mathrm{R}^{2} \geq 0.99\right)$. The Langmuir model assumes that the adsorption of the metal ions occurs on a homogenous surface by monolayer without any interaction between the adsorbate and adsorbent.

The Freundlich isotherm assumes that the uptakes of metal ions occur on a heterogenous surface by multilayer adsorption and that the amount of adsorbate adsorbed increases infinitely with an increase in concentration. It can be expressed in the linear form as follows ${ }^{12}$ :

$$
\log \mathrm{q}_{\mathrm{e}}=\log \mathrm{K}_{\mathrm{F}}+1 / \mathrm{n} \log \mathrm{C}_{\mathrm{e}}
$$

where $\mathrm{K}_{\mathrm{F}}\left(\mathrm{Lmg}^{-1}\right)$ and $\mathrm{n}$ are constants which are considered to be the relative indicators of adsorption capacity and adsorption intensity. A plot of $\log q_{e}$ vs $\log C_{e}$ gives a linear trace with a slope of $1 / n$ and intercept of $\log \mathrm{K}_{\mathrm{F}}$.

Adsorption of As(III) onto the Fe-CPW gives the linear relationship with Langmuir and Freundlich isotherm which are shown in Figure 4 and Figure 5. Langmuir and Freundlich parameters are determined from the slope and intercept of their respective plots and results obtained are presented in Table 1. A comparatively high value of correlation coefficient for Langmuir adsorption as compared to Freundlich adsorption isotherm indicated that the adsorption process closely fits to the Langmuir isotherm model. The maximum adsorption capacity of Fe-CPW was found to be $50 \mathrm{mg} / \mathrm{g}$.

Table 1: Langmuir and Freundlich parameters for the adsorption of As(III) onto $\mathrm{Fe}-\mathrm{CPW}$.

\begin{tabular}{|l|l|l|l|l|l|l|l|}
\hline Adsorbent & $\begin{array}{l}\mathrm{q}_{\mathrm{m}} \text { exp. } \\
(\mathrm{mg} / \mathrm{g})\end{array}$ & \multicolumn{4}{|l|}{ Langmuir Isotherm } & \multicolumn{2}{l|}{ Freundlich Isotherm } \\
\cline { 3 - 8 } & & $\begin{array}{l}\mathrm{q}_{\mathrm{m}} \\
(\mathrm{mg} / \mathrm{g})\end{array}$ & $\begin{array}{l}\mathrm{b} \\
(\mathrm{L} / \mathrm{mg})\end{array}$ & $\mathrm{R}^{2}$ & $\mathrm{~K}(\mathrm{mg} / \mathrm{g})$ & $1 / \mathrm{n}$ & $\mathrm{R}^{2}$ \\
\hline Fe-CPW & 45.78 & 50 & 0.873 & 0.9950 & 2.51 & 0.559 & 0.9730 \\
\hline
\end{tabular}




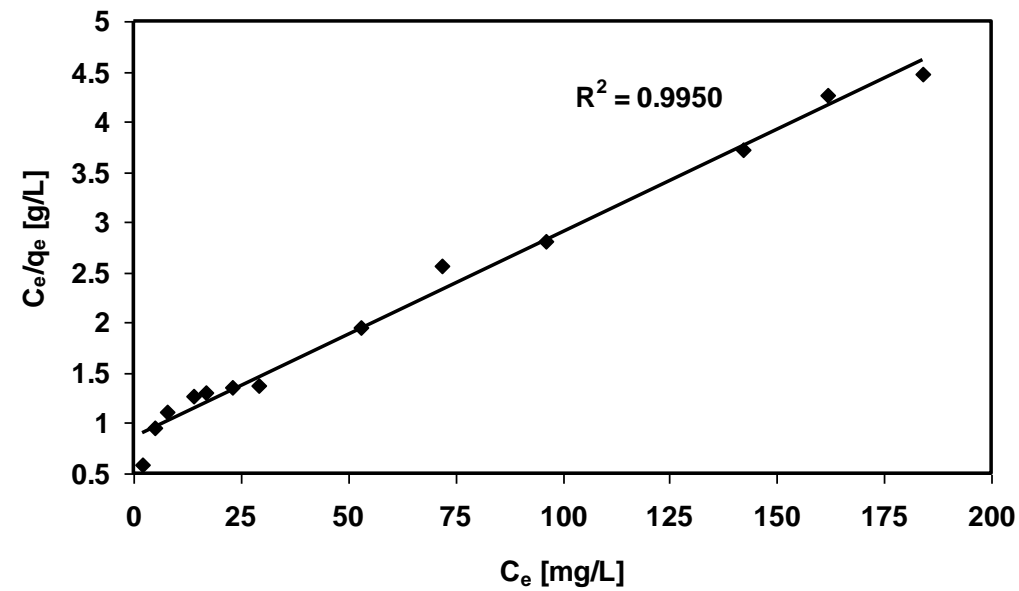

Figure 4: Langmuir adsorption isotherm plot for adsorption of As(III) onto $\mathrm{Fe}-\mathrm{CPW}$.

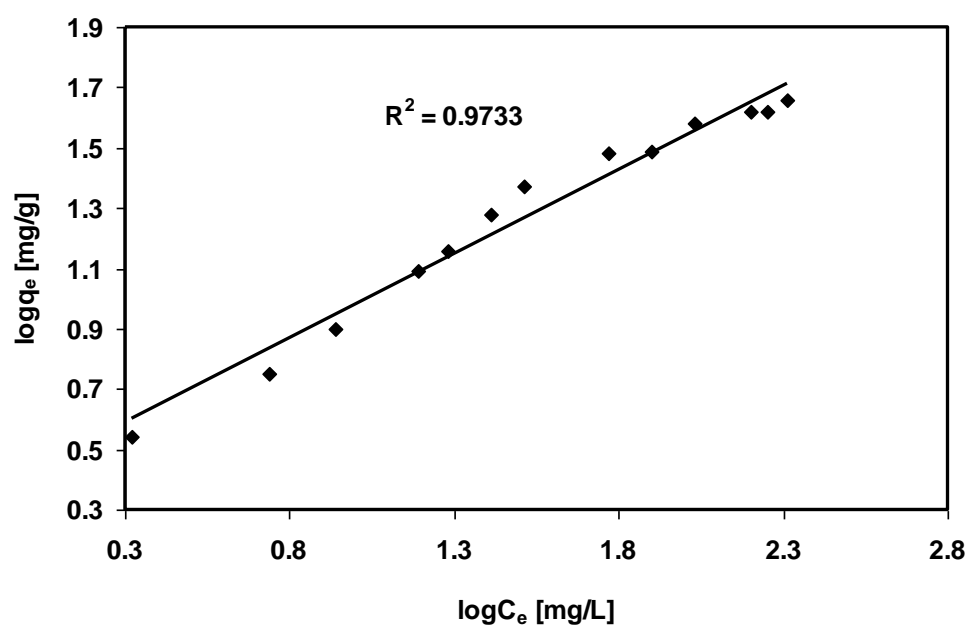

Figure 5: Freundlich adsorption isotherm plot for adsorption of As(III) onto Fe-CPW.

\section{Effect of contact time}

Batch kinetic experiments were performed to determine the time required for the As(III) binding process to reach equilibrium. Figure 6 shows the time profiles (5 to 130 minutes) for As(III) removal by Fe-CPW in batch system at optimum $\mathrm{pH}$ and containing an aqueous $25 \mathrm{~mL}(20 \mathrm{mg} / \mathrm{L}) \mathrm{As}$ (III) solution and $25 \mathrm{mg}$ of adsorbent. As shown in Figure 6, the removal percent of As(III) by adsorption onto FeCPW was increased with contact time and attain saturation in about 120 minutes. The removal percent of $\mathrm{As}(\mathrm{III})$ increases initially due to the presence of large surface area of the adsorbent being available for the adsorption of As(III). It is also relevant to point out that, since the active sorption sites in a system have a fixed number and each active site can adsorb only one ion in a mono layer, the arsenic uptake by the adsorbent surface will be rapid initially, slowing down as the competition for decreasing availability of active sites intensifies by the arsenic ions remaining in solution. ${ }^{13}$ Thus the required equilibrium time for the adsorption of As(III) onto FeIII-CPW was 2 hours. 


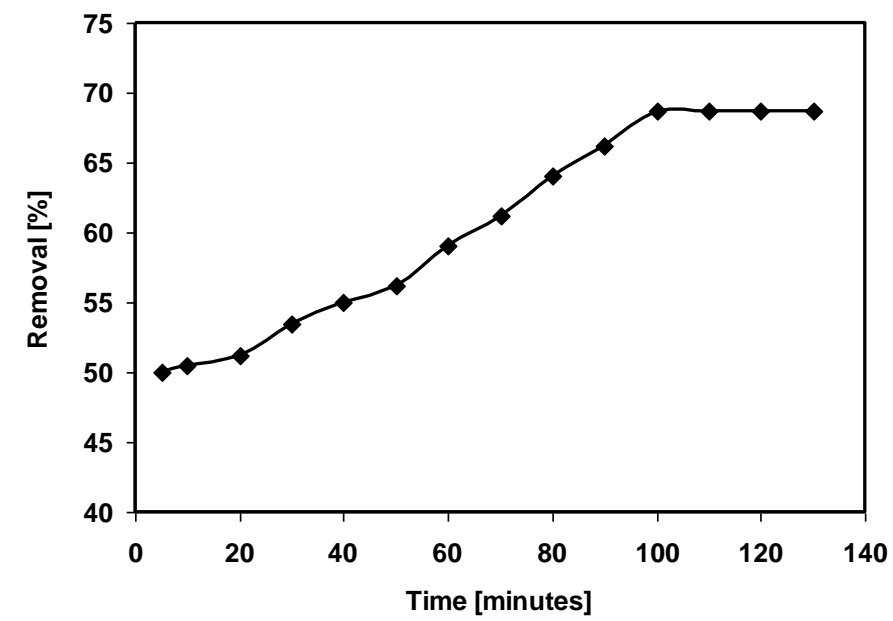

Figure 6: Effect of contact time on adsorption of As(III) onto Fe-CPW.

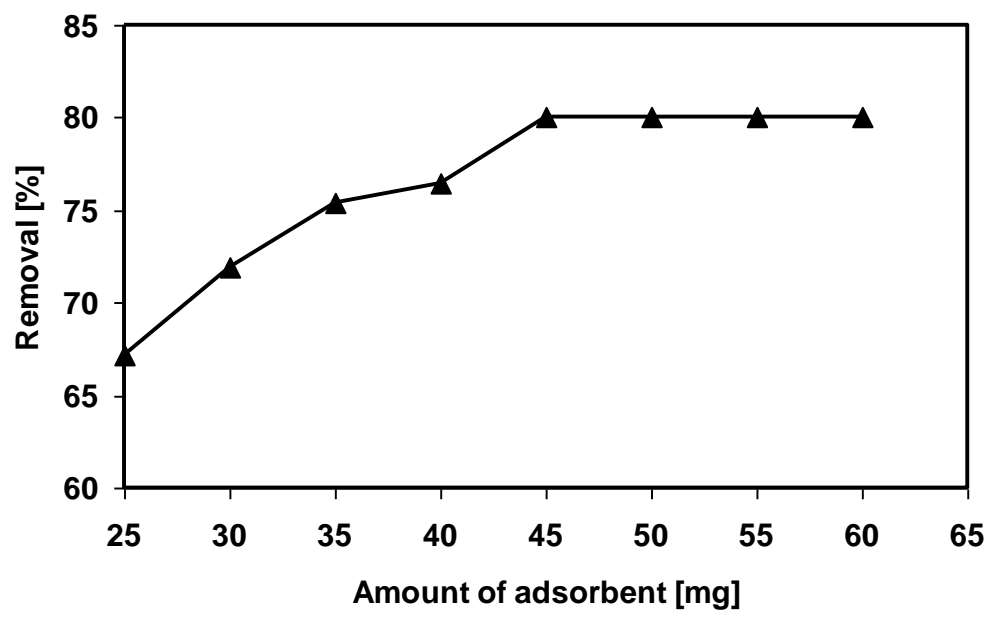

Figure 7: Effect of adsorbent dose on adsorption of As(III) onto Fe-CPW.

\section{Effect of adsorbent dose}

The extent of As(III) removal as a function of Fe-CPW dose (25 to $60 \mathrm{mg}$ ) in batch system maintained at $\mathrm{pH} 9$ and containing an aqueous $20 \mathrm{mg} / \mathrm{L} \mathrm{As}$ (III) solution was studied. The results are presented in Figure 7. The percent removal of As(III) increased from 67 to $80 \%$ when the dose of FeCPW was increased from 25 to $60 \mathrm{mg}$. It can be observed that the percentage removal of As(III) increases with increase in adsorbent dose from 25 to $45 \mathrm{mg}$ then it remains constant. This suggests that after a certain dose of adsorbent, the maximum adsorption is attained and hence the amount of ions remain constant even with further addition of dose of adsorbent. The increase in As(III) adsorption percentage with increase in adsorbent dose may be due to greater availability of the exchangeable sites or surface area at higher dose of the adsorbent ${ }^{14 .}$ 


\section{Conclusions}

A low cost bio-adsorbent for removal of As(III) from aqueous solution was prepared from pomegranate fruit waste. After treatment with concentrated sulphuric acid it was loaded with Fe(III) to analyze its efficiency for removal of arsenic. Its efficiency for removal of arsenic was tested in batch mode of experiments. The effects of $\mathrm{pH}$, initial arsenic concentration, adsorbent dose and contact time on adsorption of $\mathrm{As}(\mathrm{III})$ onto Fe-CPW were investigated. The adsorption of As(III) was found to be strongly dependent upon $\mathrm{pH}$ of the solution. The optimum $\mathrm{pH}$ for maximum removal of As(III) was found to be 9 . At optimum $\mathrm{pH}$ values, $70.7 \%$ of $\mathrm{As}$ (III) removal was achieved. The equilibrium time for the adsorption of $\mathrm{As}(\mathrm{III})$ onto Fe-CPW was found to be 2 hours.

The adsorption isotherm data were tested for both Langmuir and Freundlich isotherm models and model parameters were evaluated. Based on regression coefficient $\left(\mathrm{R}^{2}\right)$ values, the adsorption isotherm data were best fitted to Langmuir isotherm $\left(\mathrm{R}^{2}\right.$ value greater than 0.99$)$ model than Freundlich model. The maximum adsorption capacity $\left(\mathrm{q}_{\max }\right)$ for adsorption of $\mathrm{As}(\mathrm{III})$ onto Fe-CPW was found to be $50 \mathrm{mg} / \mathrm{g}$. In conclusion, Fe-CPW might be a suitable adsorbent for the removal of As(III) from aqueous solutions.

\section{Acknowledgements}

The authors are very thankful to the Head of the Department, Central Department of Chemistry, Tribhuvan University, Kirtipur, Kathmandu, Nepal for providing the available research facilities to conduct this research work.

\section{References}

1. Le. Zeng, Alberta Research Counil, 2003, 37, 4351.

2. K.N Ghimire, K. Inoue, J. Nep. Chem. Soc., 2007, 22, 41.

3. K.N. Ghimire, K.Inoue, K.Makino, Water Res., 2003, 37, 4945.

4. D.M and S.S etal., E-Journal of Chemistry, 2009, 6, 1035.

5. M. Bissen, F.H. Frimmel, J. Anal. Chem., 2000, 367, 51-55.

6. D. Pokhrel, B.S. Bhandari, T. Viraraghavan, Environmental International, 2009, 35, 157-161.

7. I. Rau, A. Gonzalo, M. Valiente, Journal of Radioanalytical and Nuclear Chemistry, 2000, 246, 597-600.

8. A.K. Pettersson, B. Karlberg, Anal. Chim. Acta, 1997, 354, 241.

9. B.K. Biswas, K. Inoue, K.N. Ghimire, H. Kawakita, K. Ohto and Hiroyuki Harada, Sep. Sci. and Tech., 2008, 43, 2144-2165.

10. G. McKay, M.S.Otterburn, J.A. Aga, Water, Air, Soil Pollut., 1985, 24, 307

11. G. Crini, H.N. Peindy, F. Gimbert, Sep. Purif. Technol., 2007, 53, 97.

12. H.M.F. Freundlich, Phy. Chem., (Leipzig), 1906, 57A, 385-470.

13. I. Langmuir, J. Am. Chem. Soc., 1918, 40(9), 1361-1368.

14. Y. Li, Fu-S. Zhang, Fu-R. Xiu, Science of the Total Environment, 2009, 407, 5780-5786. 